\title{
The Alchemy of Sound: The Power of Spoken Language in a Very Visual World
}

\author{
By Lucy Bednar*
}

In our highly visual world, spoken language is often neglected as a tool that can contribute much to students' linguistic competence. By privileging textual literacy over oral literacy, schools may be neglecting a dimension of language that students could greatly profit from, especially in a world where spoken language, oral tradition, and narrative are commanding increased attention. The author was given an opportunity to teach a university-level class focusing on the sound of language as it relates to listening/reading and speaking/writing. The semester-long class, whose goal was increased awareness of and appreciation for the value of spoken language, included work with audiobooks, oral interpretation, and speech as it relates to writing. The author provides some theoretical context for her approach, reports on what she observed while teaching the class, and includes how students themselves responded to the emphasis on spoken language as a means to improved literacy.

Keywords: audiobooks, literacy, oral interpretation, orality, pedagogy

\section{Introduction}

For centuries we have equated literacy with the ability to read written or printed text. We have assumed, as Eric Havelock (1986) says, "that writing is identical with language-in fact, that writing is language" (p. 112), even though we know that spoken language preceded written language by centuries, and that words on a page are actually symbols representing the sounds of language. As Walter Ong (1982/2006) reminds us, "Oral expression can exist and mostly has existed without any writing at all, writing never without orality" (p. 8). Over the past twenty to thirty years, our understanding of literacy has been expanded to include visual literacy, the ability to read images; and most recently, multimodal literacy, the ability to read text, image, and sound combined. Changing literacies demand changes in how students are taught to communicate. As a result, writing classes now routinely include some practice in visual or multimodal rhetoric, styles of communication that are especially appealing to students who have grown up with smartphones and video games. Nonetheless, the sound of language in and of itself remains the least used option in this contemporary rhetorical toolbox. Are we not neglecting an important dimension of language by neglecting sound? And are we not doing our students a disservice by not exploring the possibilities it offers to improve their linguistic competence-in listening, reading, speaking, and writing?

\footnotetext{
* Associate Professor, School of Writing, Rhetoric and Technical Communication, James Madison University, USA.
} 
My inquiry into how the sound of language can affect literacy in all of its manifestations began with my interest in the growing popularity of audiobooks and whether or not they could be used profitably in an academic setting to enhance students' reading skills by way of their listening skills. I was able to experiment with some of my ideas when the university where I work gave me the opportunity to teach a semester-long Honors class called Audiobooks and the Reassertion of Orality. The class highlighted the connection between reading and listening by focusing on audiobooks, on how the elements of narrative are used in a variety of genres, on the crucial importance of narrative voice, and on how that voice is created by the author, interpreted by various readers, and ultimately processed by listeners. Based on my own observations and on student feedback, collected through written responses and through midterm and end-of-term focus group sessions, I concluded that audiobooks alone were perhaps too narrow a focus for such a class-especially for a group of students representing a variety of academic disciplines. I redesigned the class to include not only audiobooks but also oral interpretation and the relationship of spoken language to writing.

In the spring of 2015 I taught the "new and improved" version of the class, now called The Sound of Language: Audiobooks, Oral Interpretation, and the Power of Speech in a Digital World. The new class fell neatly into four units, each with a slightly different focus, the later units building on the earlier ones: from theory to listening, from listening to speaking, and from speaking to writing. Unit 1 was built largely on a detailed discussion of Walter Ong's (1982/2006) seminal text, Orality and Literacy: The Technologizing of the Word; Unit 2 focused on audiobooks; Unit 3 on oral interpretation; and Unit 4 on the connection between speaking and writing. Each unit was grounded in the concept of voice and what voice can mean in both a literal and a figurative sense. In this paper I discuss the constructs of interest that rose to the surface over the course of the semester.

\section{Theoretical Context}

Students often see language as a medium used to convey information and not much more, a notion exacerbated by the Information Age, which fosters the belief that information alone constitutes knowledge, and that being educated means having a large storehouse of information. As a result, many students process all language efferently, to use Louise Rosenblatt's (1978/1994) term, meaning that their "attention is focused primarily on what will remain as the residue after the reading-the information to be acquired, the logical solution to a problem, the actions to be carried out" (p. 23), in other words, as one might read the directions on a bottle of cough medicine. Because students tend to approach all texts the same way, even a novel or a memoir gets reduced to not much more than a plotline involving the actions of a certain cast of characters. Students routinely look past or through the all-important narrative voice created by the author, which can have a profound effect on everything in a text. 
Many students simply equate the narrator with the author and cannot see that in doing so they ignore one of the text's most powerful communicative features. Mark Twain is not Huckleberry Finn, Virginia Woolf is not Mrs. Dalloway, and Vladimir Nabokov is not Humbert Humbert. And knowing that matters.

Enter the audiobook, a form of reading whose popularity has increased dramatically in recent years, thanks in large part to rapid advances in communication technologies and the proliferation of portable listening devices. According to the annual sales survey commissioned by the Audio Publishers Association (2015), the number of audiobooks being published each year is on the rise (25,787 in 2014), as are annual sales, mostly in the form of downloads. In 2014 audiobook sales totaled more than $\$ 4.47$ billion.

The audiobook falls into the category of "secondary orality", defined by Walter Ong (1982/2006) in Orality and Literacy as "a new orality ... sustained by ... electronic devices that depend for their existence and functioning on writing and print" (p. 11). Unabridged audiobooks are a hybrid medium, a coming together of text and technology, making it possible to listen to a book in its entirety as an oral not a written text, and to take that oral text with us as we walk, drive, or do household chores. Audiobooks are an example of what Jay David Bolter and Richard Grusin (2000) call remediation, the process by which one medium in some way refashions an older medium (p. 54). Audiobooks "remediate" written texts by retaining content while changing mode of delivery.

In Remediation: Understanding New Media, Bolter and Grusin (2000) further explain that understanding remediation requires understanding the interplay of immediacy, which dictates "that the medium itself should disappear and leave us in the presence of the thing represented" (pp. 5-6), and hypermediacy, which "leads us to become aware of the new medium as a medium" (p. 9). Audiobook listeners often become so caught up in listening to a book, fiction or nonfiction, that the narrator becomes transparent; at the same time, listeners can also become hyper-aware of the quality of the narration, since this dimension, which adds a layer of interpretation to the experience of listening, is the essence of the new medium. Thus, audiobooks enhance both transparency, by delivering the text as a disembodied voice, as well as visibility, by heightening awareness of that voice. What might audiobooks offer to students who have for most of their academic lives processed texts only as marks on a page?

\section{Listening/Reading}

As part of their coursework in the Sound of Language, students listened to several short pieces, chosen specifically to demonstrate what a literal voice might add to the voice inherent in a written text.

- They especially liked "Bingo", a story by Davida Adedjouma told by a woman who speaks in African American Vernacular. The story 
acquires a kind of dynamism when read aloud that mute words on the page cannot give it. The story provides a good foundation for a discussion of tone, because to understand the full meaning of the story, students have to look past the narrator's light-hearted delivery to hear the darker realities it conveys.

- Students also enjoyed listening to several varieties of English different from the American English they grew up with: Craig Ferguson's Scottish brogue in American on Purpose, Lisette Lecat's African lilt in Alexander McCall Smith's The No. 1 Ladies' Detective Agency, and John Lee's melodic East Indian rhythms in Aravind Adiga's The White Tiger.

- Listening to the first few minutes of Ambrose Bierce's short story "An Occurrence at Owl Creek Bridge" as read by several different narrators proved especially useful in illustrating how the voice used to tell a story can affect a listener's response to it. During a lively discussion about which narrated version of the story was best and why, it became clear that not all narrative interpretations are created equal.

All students in the class also read and discussed two complete audiobooks, one fiction and one nonfiction. To close the unit, each student presented a short report on an audiobook of his or her choice.

The nonfiction book that we all listened to was Frank McCourt's memoir of his boyhood, Angela's Ashes, winner of a 1996 Pulitzer Prize. McCourt himself reads the book, so author, textual narrator, and oral narrator are all the same voice, a relatively rare occurrence in the business of audiobook production. In his memoir, McCourt remembers his boyhood in the town of Limerick during the 1930s and 40s, after his family had moved back to Ireland from New York City, where his Irish immigrant mother and father had met and started a family.

McCourt's childhood, when viewed objectively, might seem like a series of major and minor tragedies. He loses a sister, then twin brothers, to illness. His father, "a shiftless loquacious alcoholic" (p. 11), cannot hold a job and often gets drunk on the meager public assistance money he is given. His mother, "pious defeated ... [and] moaning by the fire" (p. 11), is forced to seek charity at the St. Vincent de Paul Society, and when things are particularly bad, to beg for food. Despite her devotion to her family, Frank's mother is uneducated and overburdened; as a result, she often fails to act when action is called for, as when Frank contracts typhoid and later a very serious eye infection. Frank is rejected when he applies to be an altar boy, and when he attempts to get into high school, even though he comes highly recommended by the headmaster of Leamy's National School.

Throughout the book, the boy Frank has to deal with poverty, prejudice, small-mindedness, and cruelty-from government officials, "pompous priests, bullying schoolmasters" (p. 11), and from disapproving members of his own extended family. This description might lead one to believe that McCourt's memoir is imbued with anger and resentment. It is, in fact, one of the most 
engaging memoirs one could possibly hope to read, and is nothing short of hilarious in many places. The complexity of McCourt's memoir is in large measure the result of the complex voice that tells the story.

Before we discussed McCourt's book, I asked my students to describe the voice that they heard in the audiobook, deliberately leaving my question vague and open-ended. Most of my students read my use of the word "voice" quite literally. As a result, they commented on McCourt's appealing Irish accent as well as his use of colorful Irish vernacular: a pram with a bockety wheel, a dog named Macushla, a fellow student called a doddering omadhaun (or fool) by his teachers. They also commented on the feel of authenticity that hearing McCourt's own voice gives to the audiobook. Some students described the voice as that of a boy, but where some heard the humor in the boy's observations, some saw only the sadness of his life. One student described the voice as "complaining" and "plaintive", one that draws us into "the visceral, abusive experience of a poverty-devastated child and the dysfunctional parenting structure of ill-educated families".

Only two students commented on the complexity of the voice. They understood that although McCourt speaks as a child throughout the book, that child-like voice is tempered by the voice of the adult McCourt looking back on his childhood. One of those students came closest to capturing the complexity of the book's narrative voice: "The voice that I hear in this book is one of both a child and a man looking back at his childhood. He has created a harmony [between] the way he looked at the world as a child and the way it actually was. The narrator is nostalgic for this past despite the poverty he endured." The older McCourt is certainly reinterpreting the experiences of his childhood through the lens of age and wisdom. Nonetheless, he does not attempt to hide the poverty, prejudice, or cruelty that were evident everywhere in his life. We can glimpse that harsh reality even in the retelling of a comic incident involving his fourth class schoolmaster's devotion to Euclid. Mr. O'Neill, called Dotty because he was "small like a dot" (p. 151), tries to impress on the boys in his class why Euclid is so important:

- Without Euclid, boys, mathematics would be a poor doddering thing. Without Euclid we wouldn't be able to go from here to there. Without Euclid the bicycle would have no wheel. Without Euclid St. Joseph could not have been a carpenter for carpentry is geometry and geometry is carpentry. Without Euclid this very school could never have been built.

- Paddy Clohessy mutters behind me, Feckin' Euclid.

- Dotty barks at him.... And what, Paddy, were you saying to McCourt?

- I said we should get down on our two knees and thank God for Euclid.

- I'm sure you did, Clohessy. I see the lie festering in your teeth. What do I see, boys?

- The lie, sir.

- And what is the lie doing, boys?

- Festering, sir.

- Where, boys, where? 
- In his teeth, sir.

- Euclid, boys, was a Greek. What, Clohessy, is a Greek?

- Some class of a foreigner, sir.

- Clohessy, you are a half-wit. (p. 152; audiobook chapter 6, 1:40-3:05)

The voice that we hear in this memoir is deceptively simple: at first glance that of a man pretending to be his childhood self, but upon closer inspection, something more sophisticated. It becomes obvious that the guileless innocence and deceptive simplicity of the voice contribute to an intricate tapestry woven of content and tone, each influencing the other in arresting ways. The sometimes horrific events of Frank's childhood are described by the adult McCourt in a matter-of-fact tone of innocence and wonder, but if we listen closely, we can hear that the intertwining of the two voices conveys a great deal more than a child's perspective. We can hear the adult McCourt describing his life in a voice that conveys sorrow, confusion, and regret, but more importantly, love, understanding, and forgiveness. McCourt is not blind to the shortcomings of his family or his country, but he accepts them and embraces everyone who was part of his life, even his father, who eventually abandoned his family. The ability to create a voice this complex, one that can convey multiple layers of meaning simultaneously, requires considerable talent and craftsmanship.

When asked to explain certain passages in the audiobook, many of my students began to realize that they had indeed missed the complexity inherent in McCourt's voice, a complexity that contributes much to the depth and quality of the book. I do not for a moment suggest replacing printed books with audiobooks. However, I do believe that incorporating the use of sound into the study of literature certainly warrants more attention than we have given it to date.

\section{Speaking}

The focus on audiobooks was followed by a short unit on oral interpretation, during which students had an opportunity to experiment with using their own voices. I was surprised to learn from my focus group participants that the class enjoyed this part of the course much more than I had anticipated. Typically, students dislike making oral presentation; some even avoid taking classes that require such presentations. So I was truly surprised when I heard student after student recommend expanding this part of the course to include more work with oral interpretation.

Perhaps I should not have been surprised by my students' recommendation that this part of the course be expanded. Upon reflection, I realized that the ability to speak well, whether in public or private situations, is an essential skill in the $21^{\text {st }}$ century. And even though most university students are required to take a basic class in public speaking, once that class is over, they may not be given other opportunities to speak in class, or they may be given such 
opportunities but not the essential follow-up activity of critiquing how well they have spoken. The skill is simply not emphasized enough, nor is it incorporated as much as it could be into classes outside of Communication Studies. Some of my students may have been uncomfortable with the requirement that they read out loud, but they recognized the value of this activity, one that gave them an opportunity to interact with a text and experience the challenges of presenting that text well. I came to see this activity as very important to my objectives in teaching the class.

A number of very good basic texts on oral interpretation and performance are available, each providing useful perspectives on how to incorporate oral work into a class along with solid rationales for doing so. By way of example, in Oral Interpretation, Charlotte Lee and Timothy Gura (2001) point out that preparing to read a piece out loud requires students to consider a number of key features, all of which enhance their awareness of linguistic complexity:

- They must pay some attention to the connotative and denotative meanings of the words used in the text if they are to orally interpret the text successfully (pp. 26-27).

- They must determine who "relates the experiences in a text, whether the text is fictional or true, poetry or prose, dramatic or undramatic" (p. 28). This awareness of persona, of course, relates to the importance of the narrator discussed above, but comes at it from a different direction: students understand persona not through their ability to identify it but through their ability to recreate it.

- They must also identify locus. In other words, from what vantage point does the persona speak: inside the events, on the periphery of them, or outside of them? (p. 29). Locus refers to both a physical location as well as a psychological position (p. 29).

Lee and Gura (2001) emphasize the importance of understanding a text before it can be effectively performed. "You cannot perform what you do not know, and you cannot shape your rehearsal until you understand the shape of what you are rehearsing" (p. 25). Lee and Gura also discuss the importance of seeing the voice as an instrument that can be tuned. More practice with speaking aloud and interpreting texts gives students opportunities to experiment with voice and develop it, including knowing how to control their breathing, how to speak clearly and loudly enough, when to increase and when to decrease volume, when to speed up and when to slow down, when to pause, when to infuse emotion into what they are saying and when to remain cool (pp. 76-88). In addition, Lee and Gura remind us that the body is also an instrument, and beyond learning how to control their breathing, reading aloud also teaches students about the importance of posture, gesture, and eye contact (pp. 117-129).

In Theories of Performance, Elizabeth Bell (2008) focuses on the theories that "have been central to the complex and dynamic relationship between performance and communication" (p. 6). Using the work of communication 
theorist James Carey (1988), Bell discusses two very different models of communication-both important in a world that is steadily growing both larger and smaller at the same time. According to Carey, the Transmission Model emphasizes sending, transmitting, or giving information to others across vast distances (as cited in Bell, p. 7). We are familiar with this type of communication in many different guises, including satellite radio and TV, the World Wide Web, and smart phones. The Information Age gets its name in large measure from the incredible ease with which we now can access and transmit information. The Ritual Model, on the other hand, creates, maintains, and transforms reality through its emphasis on presence and immediacy. This emphasis on presence and immediacy was important to me in my attempts to bring language to life for my students. It demonstrates how language is often used to create or alter reality, something that many students often do not truly comprehend.

Bell further explains that many of our social interactions are, in fact, performances that function in different ways. They can be constitutive, meaning they have the capacity to help us create identity (pp. 19-20). They can be epistemic, meaning they are a way of gaining knowledge about ourselves, others, and the world around us (pp. 20-22). And they can be critical, meaning that they can be critiqued, and by way of critique, analyzed, evaluated, and improved (pp. 24-25). Thus, developing performance skills can be seen not only as important to the practical business of negotiating our private and public interactions but also as important to discovering who we are.

The most popular class in this unit was one that I did not teach. I invited Katie, a graduate student from my university's School of Communication Studies who also works with the university's speech team, to conduct a class on public speaking. As part of her lesson, Katie divided the class into teams of two. Each team was given the lyrics to a popular song, then given some preparation time to choose a single stanza to read out loud to the rest of the class. However, each team member was also instructed to read the lines using a specific tone of voice, and no two were alike. By way of example, my student partner and I were given the lyrics to a song sung by a young man examining his relationship with his girlfriend (Sam Smith's "Stay with Me"). Her copy instructed her to sound "pleading", and my copy instructed me to sound "frustrated".

Focus group participants pinpointed several reasons for the class's positive response to this activity. They liked its impromptu nature, especially because no one could opt out, and even the quiet students participated without protest. They enjoyed being thoroughly engaged in the activity and did not mind looking a bit foolish. They added that requiring students to leave "their comfort zone" was a good way to learn because it made good use of linguistic intelligence enhanced by body intelligence. Because "students perceive a strong connection between play and social development, and a general relation between play and learning", and because they actively created the learning experience, they were not simply passive recipients of information (Conley, 2008, pp. 156-157). 
During this unit of the course, I also gave students additional opportunities to read aloud: They took turns reading "Little Red Riding Hood" as well as Roald Dahl's unorthodox version of "The Three Little Pigs". Because fairy tales are most often read to small children, and we naturally use a very expressive voice to do so, the students felt less inhibited about reading very dramatically. The experience demonstrated to them that a clear awareness of audience is essential to good communication, both spoken and written. To conclude the unit, students read aloud a short piece of their own choosing: a poem, a song, or an excerpt from a story, essay, or novel. Each of these assignments was in effect a mini problem-solving endeavor. Students focused on an objective, deployed their approach to meeting that objective, and then had an opportunity to gauge whether or not the objective had been achieved-by way of feedback from their peers as well as personal assessment.

It was clear from their remarks that they enjoyed participating in the creation and presentation of an oral text. As noted above, many students suggested the addition of more oral activities, including:

- Rehearsing and performing short radio plays, complete with sound effects.

- Constructing an impromptu oral narrative based on a series of images that I would project to the entire group.

- Taking spoken notes on a reading assignment.

- Submitting an assignment in audio format, the most logical being one of the relatively short assignments requiring students to describe and analyze a communication situation that they observed or were part of. (Such an assignment would give students an opportunity to narrate what they observed, listen to their own narration, critique its quality, and revise both content and delivery if necessary-a process similar to what they might do with a written assignment.)

Although this unit was the shortest in the course, it proved to be an important one, in part because it was popular, but also because it opened the door to an in-depth discussion of language. Typically, at the university level, silent reading is seen as a more advanced skill than reading aloud. But much that contributes to all-around literacy can be gained from the practice of reading aloud, including a greater awareness of language as language. Not only do students gain an understanding of and appreciation for the value of expressiveness, pacing, rhythm, and the use of pauses for emphasis or dramatic effect, but they also gain an awareness of and appreciation for how these paralinguistic elements can affect their understanding of linguistic elements, such as syntax, sentence structure, and word choice. 


\section{Writing}

The use of speech to improve writing skills is not a new concept. It has been advocated over the years by writing instructors and tutors, and by researchers like Peter Elbow and Cynthia Selfe. In his latest book, Vernacular Eloquence: What Speech Can Bring to Writing, Elbow (2012) advocates combining what's best about "speaking onto the page" with what's best about carefully crafting a piece of writing to create prose that is understandable and approachable. He delineates how speech can be used profitably for the generation and development of ideas during the drafting process and for skillful revision when preparing a text for its final written form. He contends that we are "well into a culture that invites spoken language into correct writing" (p. 7). And he believes that we are moving toward "a culture of literacy in which all spoken vernaculars of English will be considered valid for serious writing ... . The only standard for both writers and readers will be the primal one: is the writing any good?" (p. 7).

In "The Movement of Air, the Breath of Meaning: Aurality and Multimodal Composing", Cynthia Selfe (2009) provides an excellent overview of how written and aural composition have evolved over time. She advocates the use of aurality, an emphasis on how something sounds, not only as a mode of composition but also as a mode of knowing and learning:

My argument is not either/or, but both/and. I am not arguing against writing, the value we place on writing, or an understanding of what writing-and print-contribute to the human condition that is vitally important ... . I do want to convince compositionists how crucial it is to acknowledge, value, and draw on a range of composing modalities-among them, images (moving and still), animations, sound, and color-which are in the process of becoming increasingly important to communicators, especially within digital networks, now globally extended in their reach and scope. (pp. 641-642)

It is interesting to note that the technology of the printing press was instrumental in privileging printed text over speech. Now new technologies make it possible to resurrect orality-not necessarily to privilege it over print but to provide innovative and ever-evolving possibilities for using the sound of language as a legitimate mode of knowing and learning.

As part of their course work, students in the class were required to submit a semester report, targeting either an academic or nonacademic audience, on a topic of special interest to them, so long as it fell within acceptable parameters. By way of example, topics included the past popularity of radio dramas and their relation to the growing popularity of podcasts, the controversy over cochlear implants in the deaf community, the creation of audio fan fiction, and the importance of spoken communication to nurses. To encourage the active integration of speech into the writing process, I had my students produce the final report in a series of coordinated steps: 
- Submission of a one-page proposal, also presented informally in class and followed by questions and/or suggestions for improvement from classmates.

- Submission of a rough draft, followed by a small-group meeting with me, during which we focused specifically on content, organization, and development of ideas.

- Resubmission of the rough draft, followed by another small-group meeting with me, during which either I or the student read portions of the draft aloud while the other members of the group followed the printed text.

- Submission of the final report.

- Informal oral presentation on the completed report to the entire class.

Although I used speech in this part of the course mostly for the discussion and subsequent development of ideas, my focus group participants gave me some truly inventive ideas about how I could build on that connection in the future. One student explained her use of Dragon NaturallySpeaking, a program which converts speech into text, to "talk to herself", to work out ideas, and to begin drafting. Another student explained his use of a text-to-speech program, which he finds especially useful when he is simply tired of looking at his work and needs a new perspective on what he has written.

Without question, the sound of language can be used in many ways to enhance or improve students' writing skills. All writers can profit from articulating their thoughts and ideas aloud, with or without a live audience to hear them. Certainly a live audience can provide useful feedback, but even in isolation the act of speaking aloud can reveal dimensions of language that might otherwise remain hard to access. For unskilled writers, hearing their own words can highlight poor word choice, clumsy sentence structure, or a shifting point of view. For more advanced writers, hearing their own words can be a gateway to a discussion of prosody, including tone and rhythm. In addition, it can be a profitable way to enlarge their understanding of the elusive concept of style. Actively incorporating sound into instruction presents many possibilities for further experimentation.

\section{Conclusions}

Needless to say, communication skills are essential, especially in light of the rapid evolution of information technologies and their impact on how we live our lives in what Robert Scholes (1985) has called "the most manipulative culture human beings have ever experienced" (p. 15). Much of that manipulation, of course, happens through language. However, equipping students with truly effective listening, reading, speaking, and writing skills is no easy task in the $21^{\text {st }}$ century. Students often cannot see that language itself can be a subject of study and not just the medium by which other subjects are studied, a problem that is compounded by the fact that it is not possible to talk about language without using 
language, and by the fact that because language is so much a part of everyday life, foregrounding it sufficiently to see it as a subject of study presents no small challenge. Nonetheless, I believe it is essential that we accept that challenge. As Scholes says, "we read and write our world as well as our texts, and are read and written by them in turn" (p. xi), and language is the single most important medium by which such creations take place.

An emphasis on sound is one way of liberating language from its circumscribed existence in the pages of a book or the pixels on a screen. Sound can give language an immediacy and a vibrancy that it may lack in the eyes of many students whose experience with language is often quite limited, especially if that experience has focused only on written texts and only on language as a means of conveying information. Referring to the work of Marshall McLuhan, Eric Havelock (1986) reminds us that "the technology of electronics, so thoroughly acoustic ... reintroduced a nonlinear and richer form of communication and so perhaps of experience, reviving forms that had existed" before print assumed its dominant role in education (p. 27), when words became things on a page rather than experiences in time. In recent years, however, we have been experiencing what Havelock calls a reassertion of orality. We are moving from "quiescent space" to "dynamic sound" (Ong, 1982/2006, p. 81), a shift that can "exercise a large measure of control over the content of what is communicated" (Havelock, p. 27).

In The Sound of Language, students had an opportunity to experience language in a way that was quite new to many of them. They had an opportunity to listen, and to consider how mode of delivery affects content and subsequent response. They had an opportunity to practice and improve their speaking skills and, by way of their speaking skills, their writing skills as well.

I believe there is value in this somewhat unorthodox approach, not only for students but for teachers as well. In "Through the Comfort Zone, or Just One More Go at College Teaching", Oscar Sarmiento (2008) reminds us that "we know that by taking risks and challenging students to unravel what at first may seem obscure and absurd, we help them navigate ... experimental and experiential terrain" (p. 78). Teachers also need to leave their comfort zone, to abandon the nicely focused lecture and the tried-and-true class activity in favor of something more risky-even at the expense of appearing puzzled or uninformed. As Barbara Johnson (1987) says in A World of Difference, we should experience ignorance "as an imperative that changes the very nature of what I think I know" rather than "as a gap in knowledge" (as cited in Sarmiento, p. 80).

I would like to conclude by returning to the concept of voice and the importance of understanding what it encompasses. It includes the ability to hear multi-dimensionality, as well as possible duplicity, in a voice. It includes the ability to voice thoughts and ideas convincingly and to participate in public discourse. It includes the ability to create voice in a written text and to convey intent with grace and precision. And it includes the ability to learn by way of speaking and listening. Maybe sound really can turn lead into gold, and maybe all of our students are potential alchemists. 


\section{References}

Audio Publishers Association. (2015). Strong expansion continues for audiobook industry. Press Release. Retrieved from http://goo.gl/1M1G4z.

Conley, W. J. (2008). Play to learn. In R. L. Badger (Ed.), Ideas that work in college teaching (pp. 147-162). Albany: State University of New York Press.

Bell, E. (2008). Theories of performance. Los Angeles: Sage Publications.

Bolter, J. D. \& Grusin, R. (2000). Remediation: Understanding new media. Cambridge: Massachusetts Institute of Technology Press.

Elbow, P. (2012). Vernacular eloquence: What speech can bring to writing. New York: Oxford University Press.

Havelock, E. A. (1986). The muse learns to write: Reflections on orality and literacy from antiquity to the present. New Haven: Yale University Press.

Lee, C. \& Gura, T. (2001). Oral interpretation. (10 ${ }^{\text {th }}$ ed.). Boston: Houghton Mifflin.

McCourt, F. (1996). Angela's ashes. New York: Scribner.

Ong, W. J. (2006). Orality and literacy: The technologizing of the word. London: Routledge. (Original work published 1982)

Rosenblatt, L. (1994). The reader, the text, the poem: The transactional theory of literary work. Carbondale: Southern Illinois University Press. (Original work published 1978)

Sarmiento, O. (2008). Through the comfort zone or just one more go at college teaching. In R. L. Badger (Ed.), Ideas that work in college teaching (pp. 77-83). Albany: State University of New York Press.

Scholes, R. (1985). Textual power: Literary theory and the teaching of English. New Haven: Yale University Press.

Selfe, C. (2009). The movement of air, the breath of meaning: Aurality and multimodal composing. College Composition and Communication 60(4), 616663. 
